Intermational goumal of Medical Sciences
2009; 6(2):102-105

Research Paper

(C) Ivyspring International Publisher. All rights reserved

\title{
Endoscopic laminoforaminoplasty success rates for treatment of foraminal spinal stenosis: report on sixty-iour cases
}

\author{
Scott M.W. Haufe ${ }^{1,3}{ }^{凶}$, Anthony R. Mork ${ }^{2,3}$, Morgan A. Pyne ${ }^{3}$, and Ryan A. Baker ${ }^{3}$ \\ 1. Chief of Pain Medicine and Anesthesiology \\ 2. Chief of Spine Surgery \\ 3. MicroSpine, DeFuniak Springs, FL 32435, USA
}

$\triangle$ Correspondence to: Scott M.W. Haufe, M.D., 101 MicroSpine Way, DeFuniak Springs, FL 32435. Phone: 888-642-7677; Fax: 850-892-4212; Email: Haufe@MicroSpine.com

Received: 2009.02.09; Accepted: 2009.03.19; Published: 2009.03.22

\begin{abstract}
Background: Foraminal stenosis is an important cause of radicular and generalized back pain. In patients who do not respond to conservative interventions, endoscopic spinal surgery provides similar results to open surgical approaches with lower rates of complication, postoperative pain, and shorter duration of hospital stay.

Methods: We performed a prospective, open, uncontrolled trial of 64 patients to evaluate endoscopic laminoforaminoplasty for the treatment of refractory foraminal stenosis.

Results: Fifty-nine percent of patients had at least 75\% improvement in Oswestry Disability Index (Oswestry) and Visual Analog Scale (VAS) scores. All patients were discharged the day of surgery. Dural leaks occurred in two patients, which were repaired intraoperatively. No other adverse events occurred.

Conclusions: Endoscopic laminoforaminoplasty appears to be a safe alternative to open decompression in patients with spinal foraminal stenosis; additional controlled trials are warranted.
\end{abstract}

Key words: endoscopic laminoforaminoplasty, spinal foraminal stenosis, minimally invasive surgery

\section{Introduction}

Foraminal stenosis is an important cause of radicular and generalized back pain. Lateral root entrapment has an incidence of 8 to 11\%[1] [2][3]. A lack of signs, symptoms, and radiographic findings specific to foraminal stenosis may lead to failed treatment [4] [5], and may be the cause of pain in up to $60 \%$ of patients who remain symptomatic postoperatively [4].

Initial treatment for symptomatic foraminal stenosis is centered on aggressive conservative methods, including mobilization, activity modification, anti-inflammatory medications, steroid injections, and selective nerve root block. Patients refrac- tory to conservative management are candidates for surgical decompression.

While anterior or posterior open surgical approaches are associated with good outcome, a significant number of patients have postsurgical symptoms, including pain, weakness, and changes in sensorium. In addition, open surgical techniques are associated with significant risks. An anterior surgical approach places the patient at risk of damage to important neurovascular structures, and both anterior and posterior approaches are associated with an increased risk of infection and neurological damage. 
Endoscopic surgical techniques have been applied to vertebral surgery with good outcome. These methods are associated with a lower risk of infection and major neurovascular or organ damage, increased rate of recovery, and shorter duration of hospital stay. In this paper we present the results of an open, nonrandomized trial of endoscopic laminoforaminoplasty for the treatment of foraminal spinal stenosis.

\section{Methods}

This was a prospective study of 64 patients who underwent endoscopic laminoforaminoplasty for refractory foraminal stenosis. Inclusion criteria were foraminal stenosis documented by magnetic resonance imaging (MRI) or computerized tomography (CT) and symptoms noted on physical exam. Patients with stenosis due to either intervertebral disc or boney compression were included, and were treated with an identical operative procedure to decompress the foraminal canal. Prior to surgery, radicular pain was confirmed with either nerve conduction studies and/or nerve blocks. Exclusion criterion was prior spinal surgery. There was no sham or control group. Patients were followed by phone or personal interview for greater than 24 months postoperatively. All surgeries were performed under intravenous (IV) sedation with the patient able to communicate in order to reduce neurological injury. All the surgeries were performed on an outpatient basis, and all patients signed informed consent documents prior to surgery.

The surgery commenced as follows: Intravenous (IV) antibiotics were administered perioperatively; cefazolin was used unless there was an allergy, in which case ciprofloxacin was substituted. The procedure is performed under Monitored Anesthesia Care sedation, in which the patient is sedated with benzodiazepines and opioids but is conscious to aid in the protection of the nerves during the procedure. The entry site is determined via fluoroscopy. A scalpel is used to make a stab wound through which a guide-wire is inserted down to the facet region of the vertebral body associated with stenosis. Over this guide-wire, a commercially available dilating system is used to dilate the tissues to approximately $14 \mathrm{~mm}$. First, a $14 \mathrm{~mm}$ tube is inserted and the inner pieces are removed; this is considered the working tube. A $12 \mathrm{~mm}$ drill bit is used to create a window into the foraminal canal. This is done utilizing fluoroscopy to determine the depth of penetration of the drill unit. Electrocautery and holmium lasers are used for hemocoagulation and soft tissue removal. Once the bone and newly drilled hole is visualized, a standard mechanical burr system is utilized to grind away the lamina of the vertebral body and to widen the opening that was created with the $12 \mathrm{~mm}$ bit. Kerrisons and pituitaries are utilized during the entire process to smooth the edges of the bone that had been burred and for general debulking of soft issues and loose bone fragments. Holmium laser was also used to decompress the disc. During the entire process a general zero degree with 30X magnification is used for visualization. Once the region of the lamina and foraminal canal is properly opened, the procedure is completed and the dilation tube is removed.

Outcome measures were percent change from baseline in Oswestry Disability Index (Oswestry) and Visual Analog Scale (VAS) scores.

\section{Results}

Sixty-four patients were enrolled, including 37 males and 27 females. The age range was 32 to 90 years of age with the median age of 62 . All patients had radicular symptoms greater than 3 months and failed conservative treatments. All patients underwent epidural steroid injections and physical therapy before being considered for surgery.

Total time for the surgery was between $30 \mathrm{~min}$ utes and 1.5 hours with the mean of 50 minutes actual surgical time. Most patients were discharged within 1 hour of reaching the PACU (range 42 to 121 minutes) and all patients were discharged the same day. The only complication was dural leak, which occurred in two patients and was corrected intraoperatively with Duragen. No infection or neurovascular injury occurred.

Percent change in Oswestry and VAS are presented in Table 1. Mean follow up time was 38 months (range: $24-45$ months). Over half (59\%) of patients showed $75-100 \%$ improvement in Oswestry score, and $59 \%$ showed 75 to $100 \%$ improvement in VAS score.

Table I. Percent improvement in Visual Analog Scale (VAS) pain score and Oswestry Disability Score following endoscopic laminoforaminoplasty.

\begin{tabular}{|c|c|c|}
\hline $\begin{array}{l}\text { Percent im- } \\
\text { provement }\end{array}$ & $\begin{array}{l}\text { Number of patients } \\
\text { showing change in } \\
\text { VAS }\end{array}$ & $\begin{array}{l}\text { Number of patients } \\
\text { showing change in } \\
\text { Oswestry }\end{array}$ \\
\hline $75-100 \%$ & 42 & 38 \\
\hline $50-74 \%$ & 4 & 9 \\
\hline $25-49 \%$ & 5 & 3 \\
\hline $1-24 \%$ & 3 & 4 \\
\hline 0 (no change) & 6 & 3 \\
\hline$-1-24 \%$ (worse) & 2 & 4 \\
\hline$-25-49 \%$ (worse) & 2 & 2 \\
\hline$-50-74 \%$ (worse) & 0 & 1 \\
\hline
\end{tabular}




\section{Discussion}

Foraminal stenosis is an important cause of spinal nerve root compression that is amenable to both conservative and surgical treatments. Open surgical decompression may be carried out via a midline approach, which may be performed as interlaminar exposure, laminotomy, laminectomy, medial facetectomy, medial foraminotomy, or muscle-splitting Wiltse or lateral approach with foraminotomy [6] [7] [8] [9]. Cases requiring complete foraminal decompression may be treated with a combined interlaminar and lateral approach [6]. In a report of 65 surgical cases of lumbar foraminal stenosis, laminectomy and foraminotomy was the most common treatment (52 patients), followed by laminotomy and foraminotomy (23 patients) [10]. Results were excellent or good in 29 $(45 \%)$ and 25 (39\%) patients, respectively, at 32.5-month follow-up. These results are consistent with other small studies, with good results reported in the majority of cases [11] [12] [13] [14].

Open surgical correction is the current standard of care, but is not without risks. Blood loss, infection, prolonged hospital stay, and postoperative pain may occur regardless of surgical approach. Posterior cervical decompression requires subperiosteal stripping of the paraspinal muscles, which can result in postoperative pain, muscular spasms, and loss of function [15]. Anterior approaches are also frequently used, but carry significant risk of esophageal or neurovascular injury and damage to tissues along the plane of section, including major organs [16].

Alternative surgical techniques, such as endoscopic approaches, allow for shorter operating time, reduction in tissue exposure and manipulation, and decreased risk of damage to surrounding structures. Fessler et al. [15] reported decreases in fluid loss, length of hospital stay, and postoperative pain medication with minimally invasive techniques compared to open surgery.

Cervical microendoscopic foraminotomy/discectomy (CMEF/D) provides clinical results equivalent to those seen with traditional surgical approaches while reducing blood loss, hospital stay, and postoperative pain [15] [17]. Similar techniques for posterior decompression are reported to have similar outcomes [18] [16] [19] [20], with symptomatic improvements equal to those found with traditional surgical techniques.

Our findings of improved pain and disability scores in the majority of patients agree with other published trials evaluating endoscopic approaches for foraminal stenosis, which report positive results in
44-97\% [21] [15] [17]. All patients in our study were discharged the same day and there were no major complications. Minor dural leaks occurred in two patients, both of which were corrected intraoperatively.

Our findings are limited by the lack of a control group, preventing an adequate comparison of endoscopic laminoforaminoplasty to conventional open decompression. However, our results support the safety of endoscopic interventions and highlight the need for large scale comparative trials to further determine the relative efficacy of open versus endoscopic interventions. Results appear to be similar as conventional surgery with the possibility of fewer complications.

\section{Conclusions}

Based on data from the current study and previously published reports, the novel technique of endoscopic surgical treatment for foraminal stenosis is validated as a potentially effective alternative to open decompression. No adverse events occurred in our patient population, and pain and disability were improved to the same degree reported in the literature for open surgical approaches. Additional controlled trials are warranted to quantify the efficacy and safety of endoscopic laminoforaminoplasty relative to conventional techniques.

\section{Competing Interest}

The authors declare that they have no competing interests.

\section{References}

1. Kunogi J, Hasue M: Diagnosis and operative treatment of intraforaminal and extraforaminal nerve root compression. Spine 1991, 16:1312-1320.

2. Porter RW, Hibbert C, Evans C: The natural history of root entrapment syndrome. Spine 1984, 9:418-421.

3. Vanderlinden RG: Subarticular entrapment of the dorsal root ganglion as a cause of sciatic pain. Spine 1984, 9:19-22.

4. Burton CV, Kirkaldy-Willis WH, Yong-Hing K, Heithoff KB: Causes of failure of surgery on the lumbar spine. Clin Orthop Relat Res 1981, :191-199.

5. Macnab I: Negative disc exploration. An analysis of the causes of nerve-root involvement in sixty-eight patients. J Bone Joint Surg Am 1971, 53:891-903.

6. Jenis LG, An HS: Spine update. Lumbar foraminal stenosis. Spine 2000, 25:389-394.

7. Jackson RP, Glah JJ: Foraminal and extraforaminal lumbar disc herniation: diagnosis and treatment. Spine 1987, 12:577-585.

8. Lejeune JP, Hladky JP, Cotten A, Vinchon M, Christiaens JL: Foraminal lumbar disc herniation. Experience with 83 patients. Spine 1994, 19:1905-1908.

9. Wiltse LL: The paraspinal sacrospinalis-splitting approach to the lumbar spine. Clin Orthop Relat Res 1973, :48-57.

10. Jenis LG, An HS, Gordin R: Foraminal stenosis of the lumbar spine: a review of 65 surgical cases. Am J Orthop 2001, 30:205-211. 
11. Baba H, Uchida K, Maezawa Y, Furusawa N, Okumura Y, Imura S: Microsurgical nerve root canal widening without fusion for lumbosacral intervertebral foraminal stenosis: technical notes and early results. Spinal Cord 1996, 34:644-650.

12. Hejazi N, Witzmann A, Hergan K, Hassler W: Combined transarticular lateral and medial approach with partial facetectomy for lumbar foraminal stenosis. Technical note. J Neurosurg 2002, 96:118-121.

13. Saringer W, Nöbauer I, Reddy M, Tschabitscher M, Horaczek A: Microsurgical anterior cervical foraminotomy (uncoforaminotomy) for unilateral radiculopathy: clinical results of a new technique. Acta Neurochir (Wien) 2002, 144:685-694.

14. Johnson JP, Filler AG, McBride DQ, Batzdorf U: Anterior cervical foraminotomy for unilateral radicular disease. Spine 2000, 25:905-909.

15. Fessler RG, Khoo LT: Minimally invasive cervical microendoscopic foraminotomy: an initial clinical experience. Neurosurgery 2002, 51:S37-S45.

16. Gala VC, O'Toole JE, Voyadzis JM, Fessler RG: Posterior minimally invasive approaches for the cervical spine. Orthop Clin North Am 2007, 38:339-49.

17. Adamson TE: Microendoscopic posterior cervical laminoforaminotomy for unilateral radiculopathy: results of a new technique in 100 cases. J Neurosurg 2001, 95:51-57.

18. Khoo LT, Fessler RG: Microendoscopic decompressive laminotomy for the treatment of lumbar stenosis. Neurosurgery 2002, 51:S146-S154.

19. Perez-Cruet MJ, Kim BS, Sandhu F, Samartzis D, Fessler RG: Thoracic microendoscopic discectomy. J Neurosurg Spine 2004, 1:58-63.

20. Yabuki S, Kikuchi S: Endoscopic partial laminectomy for cervical myelopathy. J Neurosurg Spine 2005, 2:170-174.

21. Ahn Y, Lee SH, Park WM, Lee HY: Posterolateral percutaneous endoscopic lumbar foraminotomy for L5-S1 foraminal or lateral exit zone stenosis. Technical note. J Neurosurg 2003, 99:320-323. 